\title{
ANÁLISE DOS BENEFÍCIOS DO EDI PARA A COMPETITIVIDADE LOGÍSTICA DAS ORGANIZAÇÕES
}

\section{ANAL YSIS OF THE BENEFITS OF EDI FOR LOGISTICS COMPETITIVENESS OF ORGANISATIONS}

\author{
Glauco José de Carvalho ${ }^{1}$; Renato de Campos $^{2}$ \\ ${ }^{1}$ Universidade Paulista - UNIP - Araçatuba - Brasil \\ professor.glauco@hotmail.com \\ ${ }^{2}$ Universidade Estadual Paulista - UNESP - Bauru - Brasil \\ rcampos@feb.unesp.br
}

\begin{abstract}
Resumo
O conceito de EDI - Electronic Data Interchange é normalmente utilizado para determinar tecnologias de integração entre empresas. Em termos logísticos, isto implica em uma integração entre empresas na cadeia de suprimentos, envolvendo a transmissão eletrônica de dados $e$ diminuindo, assim, a intervenção humana no processo, favorecendo ainda o desempenho organizacional. Este trabalho investigou os principais benefícios do EDI para a competitividade organizacional e seu possível impacto na melhoria do desempenho logístico de quatro empresas que integram grandes redes nacionais. Por meio do estudo de casos múltiplos foi possível identificar aspectos comuns que a utilização do EDI pode favorer a estas empresas. Os resultados foram significativos e pressupõem que a utilização desta ferramenta pode agregar valor à logística, principalmente por meio da agilização dos processos, otimização dos estoques, redução de custos e melhoria do desempenho potencial. Assim, o uso do Intercâmbio Eletrônico de Dados como uma ferramenta estratégica para fins logísticos se mostrou, por meio deste estudo, uma alternativa eficiente para melhoria dos negócios e uma boa prática, capaz de alavancar vantagens competitivas não somente para as empresas isoladas, mas também para toda a cadeia de suprimentos.
\end{abstract}

Palavras-chave: logística; estratégia; competitividade; EDI.

\section{Introdução}

O conceito de competitividade organizacional, apesar de não ser inédito, conserva sua importância ao longo dos tempos e muito embora as bases competitivas e os focos estratégicos possam variar em determinados setores, por meio da inovação e do pensamento estratégico quase sempre é possível vislumbrar novas oportunidades de se alavancar vantagens competitivas, independente do segmento organizacional no qual se opera.

No caso da logística, tanto de materiais quanto de informações, as possibilidades de melhorias e inovações vêm crescendo muito nas últimas décadas. 
De acordo com Pires (2009) embora como área de atuação e conhecimento a logística já exista há muito tempo, pelo menos dois paradigmas tradicionais mudaram: O primeiro diz respeito ao conceito de agregação de valor ao produto final, o que passou a destacar a importância dos processos logísticos. O segundo refere-se aos processos de apoio, que ganharam maior importância estratégica e em muitos casos atuais chegam a ser os responsáveis pela vantagem competitiva na organização.

A logística vem se destacando recentemente como uma das principais alavancas de competitividade em empresas de diferentes setores. Sabe-se que o exercício da competição entre empresas em diversos segmentos deixou de enfatizar somente empresas isoladas e passou a ter seu enfoque na cadeia de suprimentos como um todo.

Segundo Novaes (2007) observa-se recentemente uma dinâmica nunca antes constatada na oferta de produtos. Esse dinamismo que vai se acentuando com o tempo, gera forte necessidade de acesso a informação por parte do consumidor final. Assim, a logística tem também um papel bem importante no processo de disseminação da informação, o que é facilitado por meio das tecnologias modernas de transmissão de dados.

Daí a necessidade de se investir em tecnologias de informações e otimização dos processos, o que faz com que as organizações desenvolvam métodos ágeis por meio do emprego de ferramentas modernas que possibilitam um melhor gerenciamento de seus processos logísticos e de sua cadeia de fornecimento, favorecendo assim o aprimoramento das tarefas organizacionais e a redução de custos.

As tecnologias de informação favorecem vencer os desafios de integração da cadeia de fornecimento. Essas tecnologias podem ajudar a tornar as informações logísticas mais confiáveis, a otimizar seu processamento e aumentar a velocidade de transferência de informações (DORNIER et al, 2007).

Diante deste cenário, um dos duelos consiste em identificar ferramentas que ofereçam melhor viabilidade logística para os negócios. Nesta jornada em busca da inovação tecnológica eficaz destaca-se o uso da telemática. A telemática basicamente aborda um conjunto de tecnologias de transmissão de dados resultantes da fusão entre a informática e recursos de telecomunicações, o que possibilita a captura, processamento, compactação, armazenamento e transmissão de dados, quando necessário em tempo real, entre usuários distintos, posicionados em diferentes geografias.

Entre as tecnologias de aplicabilidade logística destaca-se o EDI - Electronic Data Interchange. O EDI é um padrão de comunicação e transferência de dados baseado em ferramentas de comunicação modernas que utilizam, principalmente, a internet como base para a transmissão eletrônica de dados e documentos de modo rápido e seguro. 
Segundo Porto et al (2000) o EDI surgiu como uma ferramenta capaz de melhorar a integração e o relacionamento entre empresas, podendo ser definido como um fluxo eletrônico e padronizado de dados entre empresas, o que permite a melhoria de resultados tanto em termos operacionais quanto estratégicos.

Neste sentido, este trabalho tem por objetivo identificar, por meio de um estudo de casos múltiplos, os benefícios da utilização do EDI em empresas que ostentam um alto fluxo de movimentações de materiais em sua cadeia de fornecimento.

Pressupõe-se que a análise elaborada a partir deste estudo possibilite uma melhor compreensão quanto à possibilidade da utilização desta ferramenta logística, o EDI, por empresas que desejam potencializar sua competitividade por meio da otimização de seus processos logísticos.

\section{Desenvolvimento}

Sabe-se que empresas que desejam ser competitivas, independente do setor onde atuam, necessitam de alguma direção estratégica para nortear seus processos decisórios e suas ações no mercado atual. Neste aspecto, uma das áreas organizacionais em que as empresas possivelmente podem investir, visando a melhoria de desempenho e a conquista de resultados, é a logística.

\subsection{Competitividade Logística}

Segundo Ballou (2001) a logística envolve todas as atividades relacionadas com o planejamento e controle da produção, gestão de estoques, distribuição, movimentação de materiais, armazenagem e expedição, transporte e sistemas de comunicação.

Diversas são as definições de logística. Basicamente, a logística está relacionada com a movimentação de materiais e fluxo de informações, envolvendo o gerenciamento de toda cadeia de fornecimento, planejamento, administração e controle do fluxo, armazenamento de matérias-primas, materiais semi-acabados e produtos acabados. A função logística pode contemplar tarefas desde o ponto de origem até o ponto de consumo, com o propósito de atender às exigências dos clientes finais (CARVALHO, 2002).

Sabe-se que, na tentativa de melhoria do desempenho, empresas de diversos setores têm desenvolvido novas estratégias logísticas, uma vez que o ressuprimento e a entrega de produtos estão entre as principais atividades de suporte à função produção das empresas. Portanto, a excelência nestas atribuições logísticas pode melhorar significativamente o atendimento aos clientes, a eficiência e a confiabilidade do processo logístico, ajudando também a reduzir custos (DURSKI, 2003).

De acordo com Taylor (2005) na competição entre as cadeias de fornecimento, sabe-se que o sucesso depende do desenvolvimento e execução de uma estratégia clara para toda cadeia. Neste 
sentido, a integração entre as empresas da cadeia passa a ser fundamental. Existe uma relação básica onde quanto maior a porção da cadeia que se consegue integrar, maior a oportunidade de se construir uma cadeia de fornecimento competitiva.

A logística atualmente tem sua importância numa escala global. Os sistemas logísticos eficientes formam as bases para o comércio e a manutenção de um alto padrão competitivo. Quanto mais sofisticados forem os sistemas logísticos, e quanto mais baratas forem a movimentação de materiais, mais livre será a troca de mercadorias e maior a probabilidade de excelência na operação (BALLOU, 2008).

De acordo com Christopher (2008) uma das maneiras de se definir 'vantagem competitiva' é simplesmente pensar que as empresas bem-sucedidas geralmente são aquelas que entregam maior valor ao cliente do que seus concorrentes. Assim, a relação de custo benefício delas se torna mais atraente que a de outras empresas que atuam no mesmo segmento. Portanto, o gerenciamento logístico deveria se debruçar sobre sua capacidade de causar impacto na relação de valor percebido para o seu cliente.

Segundo Bowersox e Closs (2009) o objetivo da formação de relacionamentos de cooperação na cadeia de fornecimento é aumentar a competitividade do canal. Assim, para alcançar um alto grau de cooperação, é necessário que os principais participantes da cadeia compartilhem informações. Outro princípio importante a se destacar é a eliminação do retrabalho.

Os clientes estão se tornando mais exigentes no que se refere à qualidade das entregas, o que também leva as organizações a uma crescente busca por serviços de qualidade. Isto justifica a importância de um bom desempenho logístico dentro das empresas. Considera-se o desempenho logístico como o nível de qualidade com o qual as empresas atendem às necessidades logísticas de seus diversos clientes (VIEIRA et al, 2010).

A logística aplicada à produção, armazenagem, transporte e comunicação, pode tornar as empresas mais competitivas. A modernização e as novas tecnologias podem favorecer a sobrevivência de uma determinada empresa ou ainda torná-la uma competidora de classe mundial (KEEDI, 2011).

\subsection{EDI - Electronic Data Interchange}

Segundo Porto et al (2000) o EDI - Electronic Data Interchange permite uma rápida transferência de informações entre empresas e o aumento da capacidade de tomada de decisão devido à melhoria na qualidade das informações processadas.

De acordo com Colcher e Valle (2000), por meio do EDI pode-se alcançar uma melhoria na comunicação entre empresas de uma determinada cadeia de suprimentos, de modo que o fluxo de informação se torne mais veloz, dinâmico, econômico e eficiente. O EDI foi desenvolvido para 
facilitar a troca de documentos eletrônicos e pode ser considerado como uma das principais ferramentas utilizada pelas empresas em termos de logística de informação, envolvendo clientes e fornecedores em negócios de qualquer natureza.

O EDI, portanto, significa troca estruturada e padronizada de dados entre entidades utilizando meio eletrônico e, assim, diminuindo a intervenção humana no processo. Criado pela ANSI - American National Standards Institute, essa tecnologia consiste num formato padrão para transmissão de dados, porém, o conceito é normalmente usado para identificar tecnologias de integração entre empresas. Geralmente devido à automação entre as partes, o EDI é implementado mediante a formalização de contratos entre as empresas interessadas (GOMES; RIBEIRO, 2004).

Segundo Dornier et al (2007) o EDI não apenas torna possível transferir informações de um ponto a outro, mas permite também a transferência entre atores do mesmo setor ou setores distintos. Empresas utilizam-no mais frequentemente para transferirem informações entre suas subsidiarias (previsões, estoque, entrega) ou entre instalações logísticas (nota de entrega, pedidos, entre outros).

Independente do setor, em qualquer que seja a cadeia de suprimentos, de um extremo ao outro, em vários elos podem existir restrições logísticas muitas vezes provocadas por falhas gerenciais no processo, o que pode favorecer a ineficiência do desempenho logístico de todo segmento (VIEIRA; COUTINHO, 2008).

De acordo com Dias (2009) atualmente uma empresa é bem-sucedida na proporção de sua habilidade em rapidamente reunir, transmitir e interpretar todas as informações pertinentes aos seus processos. A complexidade e a quantidade de dados necessários para uma gestão eficaz aumentaram consideravelmente de modo que, os sistemas logísticos devem trazer uma nova abordagem para este problema, empregando capacidade de comunicações assertiva ao nível tático e ao nível operacional.

No EDI, a comunicação entre as empresas envolvidas é feita por meio de uma estrutura de rede e softwares de comunicação de dados que interligam estas empresas. Estes softwares recebem e enviam informações entre as partes envolvidas e fazem a interação com as bases de dados das empresas (PIRES, 2009).

O EDI favorece a formação de mercados eletronicamente integrados porque permite coligir grande volume de dados, reduzindo os custos de tratamento desta informação e eliminando barreiras de distâncias geográficas. O EDI além de servir como meio de troca de transações eletrônicas, provê segurança, serviços de apoio aos clientes e uma ágil recuperação das informações (GALLON; BEUREN, 2010). 


\subsection{Benefícios do EDI}

Alguns autores tais como Pizysiezning Filho (1997), Lummus (1997), Martinez e PóloRedondo (1997), e Porto (1997) concordam com alguns benefícios comuns que o EDI pode proporcionar às organizações. Entre eles destacam-se:

- O aumento de valor agregado ao negócio;

- Melhoria do critério de desempenho velocidade;

- Vantagem por meio de ganhos financeiros e redução de custos;

- Melhoria dos controles, auditorias e gerenciamentos;

- Otimização dos fluxos de informação e processos;

- Maior suporte ao processo de tomada de decisão.

Segundo Colcher e Valle (2000) o EDI pode proporcionar uma rápida transferência de dados e documentos entre as empresas, vindo a eliminar dispêndios com processos burocráticos lentos e também evitar o retrabalho.

De acordo com Gomes e Ribeiro (2004) inúmeros são os aspectos positivos que podem ser alcançados por meio da utilização de uma ferramenta baseada em EDI. Segundo os autores, entre as principais vantagens obtidas destacam-se:

- A eliminação do tempo morto;

- Maior facilidade de auditorias;

- Aumento da disponibilidade dos ativos;

- Agilidade na entrega (redução do transit time);

- Eliminação de transcrições de documentos;

- Possibilidade de acompanhamento da carga;

- Minimização de erros nas faturas de fretes;

- Envio e recebimento de dados independente de horários;

- Envio simultâneo de informação para várias entidades.

Ainda segundo Gomes e Ribeiro (2004) dentre os principais benefícios para as empresas que utilizam esta tecnologia observa-se:

- Melhoria na comunicação entre os elos da cadeia;

- Automatização da produção;

- Reforço das parcerias de negócios;

- Possibilidade de redução do preço de compras e custos diversos com estoques;

- Transmissão eletrônica de dados e documentos;

- Obtenção de dados estruturados em formato padrão;

- Suporte às estratégias modernas de produção;

- Favorece a prática do Just in Time. 
Conforme pode ser obervado, diversos são os benefícios estratégicos obtidos com a utilização do EDI, principalmente, considerando os cenários competitivos onde a otimização dos processos e a melhoria na capacidade de decisão por meio da informação ótima possibilitam uma maior eficiência (EANBRASIL, 2004).

De acordo com Ferreira e Silveira (2007) os benefícios em se utilizar o EDI remetem-se ainda à redução do consumo de material impresso, tempo reduzido de transmissão de documentos quando comparado com os meios convencionais (correios), alimentação informatizada de dados, diminuição de despesas administrativas e maior dinamismo nas transações comerciais.

As tecnologias atuais são capazes de atender aos mais exigentes requisitos por meio da vantagem do fluxo rápido de informação e com o uso do EDI as entregas podem ser ainda mais rápidas, com um custo total mais baixo (BOWERSOX; CLOSS, 2009).

Deste modo, esta tecnologia associada à logística pode proporcionar junto às empresas parceiras, não só a melhoria de suas atividades, mas também favorecer uma nova dinâmica nos processos logísticos, podendo contribuir para o aumento da vantagem competitiva em toda a cadeia de suprimentos.

\section{Método de Pesquisa}

Este trabalho seguiu uma abordagem conceitual e prática, cujos procedimentos se debruçaram sobre uma perspectiva qualitativa, fundamentada em sua essência conforme os requisitos metodológicos mais adequados para a realização do estudo.

De acordo com Santos, Rossi e Jardilino (2000) as pesquisas de natureza qualitativa se ocupam principalmente de compreender e interpretar os fatos, visando principalmente discernir e especificar um fenômeno a partir de percepções e valores manifestados nos dados coletados e nos cenários observados.

Portanto, o método de pesquisa utilizado foi o estudo de casos múltiplos (BERTO; NAKANO, 2000; YIN, 2001; VOSS et al, 2002), o qual se concentrou em quatro cenários logísticos de diferentes empresas na região de Araçatuba-SP, as quais integram grandes redes nacionais. A Figura 1 mostra como foi conduzido o estudo de casos múltiplos elaborado neste trabalho. 
Figura 1 - Condução do Estudo de Casos Múltiplos

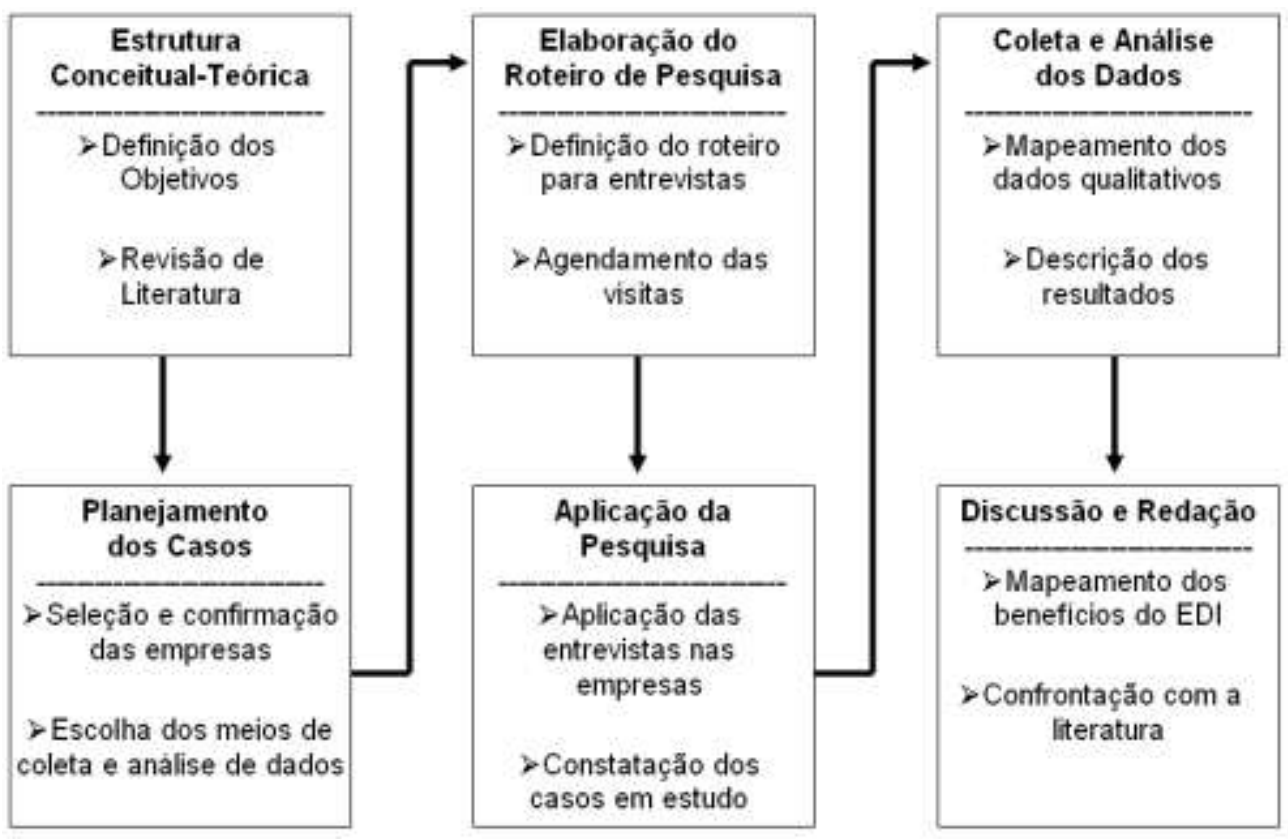

Fonte: Autoria própria (2012)

De acordo com Miguel (2007) o estudo de caso é uma espécie de histórico de um fenômeno, extraído de múltiplas fontes de evidências onde qualquer fato relevante à corrente de eventos que descrevem o fenômeno é um dado potencial para análise.

As empresas selecionadas para aplicação deste estudo foram escolhidas considerando a dimensão de suas redes logísticas, seu fluxo de materiais e a complexidade de seus processos logísticos. A amostra foi composta por quatro empresas localizadas na região de Araçatuba-SP, onde todas compõem parte de grandes redes varejistas. Estas redes, embora de segmentos variados, ostentam grandes volumes de ressuprimento e complexos processos logísticos, os quais garantem o abastecimento de seus estoques, que se encontram em constante transição.

Após a apresentação da proposta de pesquisa às empresas, foram aplicadas as entrevistas, elaboradas especificamente para este estudo. Uma vez concluída as investigações, os dados foram submetidos à análise.

Por questões de ética e privacidade, as empresas terão suas identidades preservadas. Os principais resultados encontrados podem ser observados no capítulo a seguir.

\section{Resultados}

A análise dos resultados da pesquisa permitiu a observação de informações significativas pertinentes aos benefícios do EDI nos processos organizacionais das empresas investigadas, de acordo com suas redes logísticas.

A Tabela 1 mostra o perfil organizacional da rede da qual faz parte a empresa 1. 
Tabela 1 - Perfil da rede a qual pertence a empresa 1

\begin{tabular}{ll}
\hline \multicolumn{1}{c}{ Empresa 1 } & \multicolumn{1}{c}{ Dados Gerais } \\
\hline Ramo de Atividade: & Supermercados e hipermercados \\
Número de Funcionários da Rede: & Mais de 70 mil \\
Faturamento Anual da Rede: & R\$ 16,5 bilhões \\
Quantidade de Lojas: & 550 unidades \\
Abrangência: & Nacional \\
\hline Fonte: Empresa 1 (2012) &
\end{tabular}

De acordo com a empresa 1 sua rede possui CDs (centros de distribuição) espalhados pelo país, os quais estão integrados com milhares de fornecedores. Cada uma de suas unidades, por sua vez, está interligada ao $\mathrm{CD}$ mais próximo de sua região. O fluxo de reabastecimento de suas unidades é muito dinâmico, quase diário, embora a empresa tolere manter um estoque mínimo para suportar um consumo de 15 dias, o que exige excelência e rapidez nos seus processos logísticos.

A empresa utiliza um ERP - Enterprise Resource Planning, com tecnologia Oracle, que controla toda entrada e saída de produtos na unidade. Este sistema de informação armazena e possibilita a análise de dados de até dois anos atrás e permite a previsão da demanda futura, favorecendo assim o planejamento estratégico.

Porém, todo gerenciamento é feito a partir do CD ao qual a loja está vinculada. Este por sua vez monitora os estoques da unidade e providencia o reabastecimento por meio das informações geradas pelo sistema e transmitidas via EDI.

Portanto, o sistema de informação adotado por esta rede de varejo mantém as suas unidades interligadas com os seus CDs por meio de tecnologia EDI, de modo que o padrão, as tendências e o volume de consumo nas unidades podem ser monitorados diariamente.

Assim, os níveis de estoques e a necessidade de reabastecimento são gerenciados à distância por meio de relatórios e intercâmbio eletrônico de dados gerados a partir da tecnologia EDI adotada pela empresa.

Segundo a empresa, os benefícios mais perceptíveis com a utilização do EDI são a agilidade no processo logístico, otimização, padronização do processo, redução dos itens faltantes, redução de custos logísticos e aumento da produtividade.

A Tabela 2 mostra o perfil organizacional da rede da qual faz parte a empresa 2.

Tabela 2 - Perfil da rede a qual pertence a empresa 2

\begin{tabular}{ll}
\hline \multicolumn{1}{c}{ Empresa 2 } & \multicolumn{1}{c}{ Dados Gerais } \\
\hline Ramo de Atividade: & Restaurantes \\
Número de Funcionários da Rede: & Mais de 20 mil \\
Faturamento Anual da Rede: & R \$ 1,5 bilhões \\
Quantidade de Lojas: & 350 unidades \\
Abrangência: & Nacional \\
\hline
\end{tabular}

Fonte: Empresa 2 (2012)

Segundo a empresa 2, sua rede possui dois CDs no estado de São Paulo os quais atendem todas as suas unidades. Por se tratar de uma rede de restaurantes e havendo a necessidade de manter 
alimentos frescos a capacidade de armazenagem local é baixa, o que faz com que esta organização mantenha um sistema de ressuprimento que reabastece suas unidades a cada 48 horas.

O estabelecimento utiliza um sistema de informação gerencial denominado SIAG, o qual, baseado nos históricos de vendas, gera indicadores que favorecem a projeção de vendas futuras.

Portanto, o gerenciamento logístico é feito a partir da própria unidade a qual monitora seus estoques e consumo e a partir da sugestão de compras emitida pelo sistema SIAG se determina o volume de reabastecimento, sendo o pedido de ressuprimento transmitido via EDI ao centro de distribuição.

Assim, o sistema de informação adotado por esta rede de empresas mantém as suas unidades interligadas com seus CDs por meio de tecnologia EDI, de modo que as informações de consumo e as demandas são rapidamente comunicadas favorecendo um reabastecimento preciso.

Embora os níveis de estoques e previsão de demandas não sejam gerenciados à distância, os ganhos na agilidade do processo logístico favorecem as tarefas diárias por meio de tecnologia EDI adotada pela empresa.

De acordo com a empresa 2, dentre os maiores benefícios proporcionados pelo EDI destacam-se a agilidade do processo, redução do nível de estoques, confiabilidade nas entregas e redução de custos logísticos.

A Tabela 3 mostra o perfil organizacional da rede da qual faz parte a empresa 3.

Tabela 3 - Perfil da rede a qual pertence a empresa 3

\begin{tabular}{ll}
\hline \multicolumn{1}{c}{ Empresa 3 } & \multicolumn{1}{c}{ Dados Gerais } \\
\hline Ramo de Atividade: & Varejo diversificado \\
Número de Funcionários da Rede: & Mais de 18 mil \\
Faturamento Anual da Rede: & R\$ 5,2 bilhões \\
Quantidade de Lojas: & 400 unidades \\
Abrangência: & Nacional \\
\hline Fonte: Empresa 3 (2012) &
\end{tabular}

De acordo com a empresa 3, sua rede possui um CD que funciona como uma matriz, o qual está integrado com milhares de fornecedores dos seus diversos produtos. Cada uma das lojas desta rede está interligada a este CD. Porém, existem outros dois CDs de apoio para distribuição logística localizados em diferentes estados do país.

O ressuprimento das unidades que compõem esta rede é feito a cada dois dias a partir dos próprios CDs uma vez que as unidades mantêm um nível mínimo de estoque rotativo.

A empresa utiliza um sistema ERP para o gerenciamento logístico, o qual interliga todas as unidades da rede aos centros de distribuição. Este sistema ERP informa quando é necessário reabastecer uma determinada unidade.

As informações transmitidas automaticamente por meio do EDI ao CD possibilitam a gestão do ressuprimento e aquisição de novas compras. Uma vez efetivado as compras ou as liberações 
para as entregas, as unidades recebem antecipadamente, também por meio do EDI, a remessa dos produtos que estarão a caminho.

O sistema de informação adotado e o EDI permitem que as unidades desta rede troquem informações e por meio do intercâmbio eletrônico interajam umas com as outras podendo fazer, inclusive, o remanejamento de produtos que não foram absorvidos pela demanda de uma determinada região.

Portanto, o gerenciamento dos estoques e a necessidade de reabastecimento são feitos à distância por meio de relatórios e intercâmbio eletrônico de dados gerados a partir da tecnologia EDI adotada pela empresa.

Segundo a empresa 3, as maiores vantagens com a utilização do EDI consistem na velocidade do processo, diminuição do prazo de entregas, desburocratização, otimização dos estoques e melhoria do desempenho logístico.

A tabela 4 mostra o perfil organizacional da rede da qual faz parte a empresa 4.

Tabela 4 - Perfil da rede a qual pertence a empresa 4

\begin{tabular}{ll}
\hline \multicolumn{1}{c}{ Empresa 4 } & \multicolumn{1}{c}{ Dados Gerais } \\
\hline Ramo de Atividade: & Loja de Departamentos \\
Número de Funcionários da Rede: & Mais de 7 mil \\
Faturamento Anual da Rede: & Não divulgado \\
Quantidade de Lojas: & 45 unidades \\
Abrangência: & Nacional \\
\hline Fonte: Empresa 4 (2012) &
\end{tabular}

Segundo a empresa 4, sua rede possui um único CD localizado na região sul do país. Todas as empresas desta rede estão interligadas com este CD. O fluxo de ressuprimento é diário e a empresa procura manter um nível mínimo de estoque.

A rede mantém em seu mix de produtos disponíveis aproximadamente 100 mil itens, o que a faz interagir com milhares de fornecedores a partir de seu centro de distribuição.

A empresa utiliza um sistema de informação gerencial denominado PCE, que além de controlar a rotatividade de todo produto que deixa a unidade, faz também a integração da unidade com o $\mathrm{CD}$, permitindo o gerenciamento à distância do consumo e o reabastecimento dos estoques.

Esta tecnologia empregada, por meio do EDI, permite também a integração do CD com diversos fornecedores, o que agiliza as propostas de compras e negociações.

O sistema PCE, através do intercâmbio eletrônico de dados adotado por esta rede de empresas mantém as suas unidades interligadas de modo que, a demanda e a necessidade de reabastecimento da rede podem ser monitoradas diariamente.

Deste modo, os níveis de estoques e a necessidade de ressuprimento podem ser gerenciados remotamente por meio da tecnologia EDI empregada.

De acordo com a empresa 4, os maiores benefícios advindos com a utilização do EDI remetem-se a agilidade da reposição de estoques, eficiência dos processos logísticos, praticidade e 
melhoria do desempenho logístico.

\section{Discussão}

Embora, em termos logísticos, as empresas analisadas compartilhem desafios comuns, elas apresentam cenários logísticos ostentando características próprias, uma vez que pertencem a segmentos distintos.

Estas empresas conduzem seus negócios de forma diferenciada, possuem estruturas de rede robustas e utilizam tecnologias diferentes, embora todas façam uso do intercâmbio eletrônico de dados.

As dinâmicas observadas em seus sistemas logísticos também se ajustam às necessidades individuais de cada negócio, porém, todos se mostraram complexos uma vez que buscam a integração dos variados processos organizacionais.

As empresas analisadas compõem quatro organizações que formam grandes redes nacionais. De acordo essas empresas as mesmas práticas logísticas e tecnologias aplicadas nas unidades em estudo também são utilizadas em toda a rede.

Desde modo, pressupõe-se que os benefícios do EDI identificados em cada uma das quatro empresas pesquisadas possam corresponder com suas respectivas redes.

Para fins de análise dos benefícios apontados pelas empresas estudadas com relação à utilização da tecnologia EDI nos processos logísticos, a tabela 5 mostra os principais aspectos de abordagem prática apontados pelas quatro empresas investigadas.

Tabela 5 - Mapeamento dos benefícios do EDI nas empresas analisadas

\begin{tabular}{rrrrr}
\hline Benefícios do EDI identificados nas empresas & \multicolumn{2}{c}{ Empresas } \\
Maior agilidade e velocidade no processo logístico & $\mathrm{X}$ & $\mathrm{X}$ & $\mathrm{X}$ & \\
Otimização e praticidade & $\mathrm{X}$ & & $\mathrm{X}$ & $\mathrm{X}$ \\
Desburocratização e padronização do processo & $\mathrm{X}$ & & $\mathrm{X}$ & \\
Redução dos itens faltantes e agilidade na reposição de estoques & $\mathrm{X}$ & & & $\mathrm{X}$ \\
Redução dos custos logísticos & $\mathrm{X}$ & $\mathrm{X}$ & & \\
Aumento da produtividade & $\mathrm{X}$ & & & $\mathbf{0 4}$ \\
Redução dos níveis de estoques & & $\mathrm{X}$ & & \\
Confiabilidade e diminuição dos prazos de entregas & & $\mathrm{X}$ & $\mathrm{X}$ & \\
Melhor eficiência e desempenho logístico & & $\mathrm{X}$ & $\mathrm{X}$ \\
\hline
\end{tabular}

Fonte: as empresas

Conforme mostra a tabela 5 , foram identificados nove tipos de benefícios a partir dos processos logísticos das empresas analisadas.

Os aspectos identificados e em destaque remetem-se a utilização das tecnologias baseadas em EDI, as quais, dentro destas empresas supostamente têm favorecido a execução das atividades logísticas organizacionais. 
Observa-se, que a maior parte dos benefícios identificados e mostrados na tabela 5 aparece em mais de uma empresa, o que sugere vantagens comuns a partir da utilização do EDI por empresas diferentes.

A abordagem de alguns dos elementos identificados nestas empresas reafirma os benefícios sugeridos pela literatura, conforme foram citados no item 2.3 deste trabalho.

Porém, quando os benefícios identificados nesta pesquisa são confrontados com os benefícios sugeridos pela literatura no item 2.3, nota-se que os benefícios encontrados nesta pesquisa tendem a ter uma abordagem relativamente mais prática a cerca dos resultados obtidos a partir da utilização do EDI.

Isto sugere que a tecnologia EDI, ao longo do tempo, tem sido aperfeiçoada e a experiência adquirida pelas empresas a partir de uma melhor exploração destes recursos pode estar favorecendo o alcance de resultados práticos mais tangíveis.

Portanto, os benefícios do electronic data interchange identificados neste trabalho e mostrados na tabela 5, sugerem vantagens reais e melhorias potenciais experimentadas no dia a dia da gestão de operações logísticas nas empresas pesquisadas, melhorias estas que, segundo as empresas, justificaram todos os seus investimentos em EDI.

\section{Considerações Finais}

Este trabalho investigou os benefícios do EDI na logística das organizações. A análise foi fundamentada em quatro empresas que fazem parte de grandes redes logísticas nacionais.

Por meio do estudo de casos múltiplos foi possível observar as vantagens do uso desta tecnologia para suportar os processos logísticos destas empresas, bem como, para favorecer o processo de tomada de decisão.

Os resultados foram positivos e pressupõem que o EDI, embora em alguns casos possa exigir altos investimentos, tem o seu uso justificado pelas melhorias potenciais que a ferramenta pode agregar ao negócio.

Também foi possível observar, por parte das empresas estudadas, uma preocupação no sentido de otimização de seus processos por meio do foco em estratégias competitivas eficazes que possam trazer vantagens significativas e melhorias não somente locais, como também para toda sua cadeia de suprimentos, agregando assim um maior valor ao cliente final.

Portanto, nestas empresas o uso do EDI - Eletronic Data Interchange como uma ferramenta estratégica para fins logísticos se mostrou uma boa prática capaz de alavancar vantagens competitivas para estas organizações, favorecendo o exercício dos processos logísticos diários, e ainda a gestão da informação.

Destaca-se que alguns dos benefícios do EDI documentados pela literatura e observados 
neste trabalho foram comprovados a partir dos resultados encontrados, enquanto outros benefícios, decorrentes de práticas modernas do EDI puderam ser acrescentados.

Pesquisas complementares baseadas no tema proposto poderão ainda ser desenvolvidas, considerando toda a cadeia de fornecimento, no sentido de melhor discernir os benefícios do EDI como uma ferramenta logística em outros elos da cadeia de fornecimento.

\begin{abstract}
The concept of EDI - Electronic Data Interchange is normally used to determine integration technologies between companies. Logistically, this implies in the integration between enterprises in supply chain, involving the electronic transmission of data and thus reducing human intervention in the process, still favoring organizational performance. This study investigated the main benefits of EDI for organizational competitiveness and its possible impact on improving logistics performance of four companies comprising large national networks. Through multiple case studies were able to identify common features that the use of EDI can favorer these companies. The results were significant and assume that the use of this tool can add value to logistics, primarily through streamlining processes, inventory optimization, cost reduction and performance improvement potential. Thus, the use of Electronic Data Interchange as a strategic tool for logistics proved, through this study, an efficient alternative for business improvement and good practice, able to leverage competitive advantages not only for individual companies, but also for the entire supply chain.
\end{abstract}

Key-words: logistics; strategy; competitiveness; EDI.

\title{
Referências
}

BALLOU, R.H. Gerenciamento da cadeia de suprimentos: panejamento, organização e logística empresarial. $4^{\mathrm{a}}$ ed. Porto Alegre: Bookmann, 2001.

BALLOU, R.H. Logística Empresarial: Transporte, administração, materiais e distribuição física. São Paulo: Atlas, 2008.

BERTO, R.M.V.S.; NAKANO, D.N.A. Produção Científica nos Anais do Encontro Nacional de Engenharia de Produção: Um Levantamento de Métodos e Tipos de Pesquisa. Produção, v.9, n.2, p.65-76, 2000.

cross ref

BOWERSOX, D.J.; CLOSS, D.J. Logística Empresarial: O processo de integração da cadeia de suprimento. São Paulo: Atlas, 2009.

CARVALHO, J.M.C. Logística. $3^{\text {a }}$ ed. Lisboa: Edições Silabo, 2002.

COLCHER, R.; VAlLE, A. Guia da EDI e Comércio Eletrônico. 3ed. Rio de Janeiro, 2000.

CHRISTOPHER, M. Logística e Gerenciamento da Cadeia de Suprimentos: Criando redes que agregam valor. $2^{\circ}$ ed. São Paulo: Cengage Learning, 2008.

DIAS, M.A.P. Administração de Materiais: Princípios, conceitos e gestão. $5^{\circ}$ ed. São Paulo. Atlas, 2009.

DORNIER. P.P.; ERNST, R.; FENDER, M.; PANOS, K. Logística e Operações Globais. Texto e Cases. São Paulo. Atlas, 2007.

DURSKI, G.R. Avaliação do Desempenho em Cadeias de Suprimentos. Revista da FAE, Curitiba, v.6, n.1, jan./abr. 2003. 
EANBRASIL. Guia EDI do Seguimento Calçadista. São Paulo, 2004.

FERREIRA, N.G.; SILVEIRA, M.A.P. Impactos da Informatização na Gestão e Competitividade de Supermercados. Revista de Administração Mackenzie, 2007.

GALLON, A.V.; BEUREN, I.M. Análise dos impactos do Eletronic Data Interchange nas empresas. Revista Gestão \& Tecnologia, Pedro Leopoldo, v.10, n.1, p.1-11, jan./jul., 2010.

GIL, A.C. Como elaborar projetos de pesquisa. 4.ed. São Paulo: Atlas, 2002.

GOMES, C.F.S.; RIBEIRO, P.C.C. Gestão da Cadeia de Suprimentos Integrada à Tecnologia de Informação. Pioneira Thomson Learning, São Paulo, 2004.

KEEDI, S. Logística de Transporte Internacional: Veículo prático de competitividade. 4ed. São Paulo, Aduaneiras, 2011.

LUMMUS, R.R. The Evolution to Electronic Data Interchange: Are The Benefits At All Stages of Implementation? Hospital Material Management Quarterly, 1997.

MARTINEZ, J.J.; POLO-REDONDO, Y. Internacional diffusion of a new tool: the case of Electronic Data Interchange (EDI) in the retailing sector. Research Policy, 1997.

MIGUEL, P.A.C. Estudo de Caso na Engenharia de Produção: Estruturação e recomendações para sua condução. Produção, v.17, n.1, p.216-229, Jan./Abr., 2007.

cross ${ }^{\text {ref }}$

NOVAES, A.G. Logística e Gerenciamento da Cadeia de Distribuição. Rio de Janeiro: Elsevier, 2007.

PIRES, S.R.I. Gestão da Cadeia de Suprimentos: Conceito, estratégisas, práticas e casos - Supply Chain Management. $2^{\circ}$ ed. São Paulo: Atlas, 2009.

PIZYSIEZNIG FILHO, J. Competências Essenciais e a Tecnologia de Informação: O Caso da Interchange. In MARCOVITCH, J. “Tecnologia de Informação e Estratégia Empresarial”. São Paulo: Futura, 1997.

PORTO, G.S. Estratégia e tecnologia de informação: um estudo sobre o IBM Support Center. In: PORTO, G.S. et al. Intercâmbio Eletrônico de Dados - EDI e os Impactos Organizacionais. Rev. FAE, Curitiba, v.3, n.3, p.27-29, set./dez. 2000 .

SANTOS, G.T.; ROSSI, G.; JARDILINO, J.R.L. Orientações Metodológicas para Elaboração de Trabalhos Acadêmicos. 2 ed. São Paulo: Gion Editora, 2000.

TAYLOR, D.A. Logística na Cadeia de Suprimentos: Uma perspectiva gerencial. São Paulo. Pearson AddisonWesley, 2005.

VIEIRA, J.G.V.; COUTINHO, D.P. Avaliação da Colaboração Logística entre uma Distribuidora e seus Fornecedores. Revista Eletrônica Produção e Engenharia, v.1, n.1, p.53-68, 2008.

VIEIRA, J.G.V.; YOSHIZAKI, H.T.Y.; LUSTOSA, L.J. Um Estudo Exploratório sobre Colaboração Logística em um Grande Varejo Supermercadista. Revista Produção, v.20, n.1, p.135-147, 2010.

cross ref

VOSS, C. et al. Case Research in Operations Management. International Journal of Operations and Production Management, v.22, n.2, p.195-219, 2002.

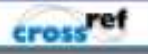

YIN, R.K. Estudo de caso: Planejamento e métodos. 2.ed. São Paulo: Bookman, 2001. 


\section{Dados dos autores:}

Nome completo: Glauco José de Carvalho

Filiação institucional: UNIP - Universidade Paulista

Função ou cargo ocupado: Professor

Endereço: Rua Alfredo Castilho, nº 263, Novo Umuarama, Araçatuba-SP, CEP: 16015-180

Telefones para contato: (18) 3301.2450 - (18) 3636.1450

e-mail: professor.glauco@hotmail.com

Nome completo: Renato de Campos

Filiação institucional: UNESP/FEB - Universidade Estadual Paulista

Departamento: Engenharia de Produção

Função ou cargo ocupado: Professor

Endereço: Av. Eng. Luiz Edmundo C. Coube 14-01, Vargem Limpa, Bauru-SP, CEP: 17033-360

Telefones para contato: (14) 3103.6000

e-mail: rcampos@feb.unesp.br

Enviado em: 05/12/2012

Aprovado em: $23 / 01 / 2013$ 